Original Research Article

\title{
Determinants, characteristics and treatment of neck pain in a tertiary care hospital in Kerala
}

\author{
Liya Roslin Joseph*
}

\begin{abstract}
Assistant Professor, Department of Pharmacology, Pushpagiri Institute of medical sciences and research centre, Thiruvalla, Kerala, India
\end{abstract}

Received: 01 November 2016 Accepted: 29 November 2016

\section{*Correspondence to:}

Dr. Liya Roslin Joseph,

Email: liyaroslin@gmail.com

Copyright: (C) the author(s), publisher and licensee Medip Academy. This is an openaccess article distributed under the terms of the Creative Commons Attribution NonCommercial License, which permits unrestricted noncommercial use, distribution, and reproduction in any medium, provided the original work is properly cited.

\begin{abstract}
Background: This study was undertaken to study the determinants, clinical characteristics and treatment pattern of neck pain in patients attending outpatient department of Physical medicine and Rehabilitation in a tertiary care hospital.

Methods: Study comprehended single patient visit. Data regarding patient demographics, characteristics of neck pain and clinical diagnosis, drugs prescribed to each patient were recorded in a pre prepared proforma. Clinician's opinion about patient's X-ray of cervical spine and the data regarding alternative treatment modalities were also noted. Data analysis was done with the help of excel 2007 and SPSS 16 statistical software.

Results: Among 170 patients included in the study $38.8 \%$ of patients were in the age group of 40-49 years with M:F ratio-1:2.9. $98.8 \%$ of patients experienced radiation of neck pain to one or both arms. Neck pain also was associated with numbness in arm $(82.4 \%)$, forearm $(61.8 \%)$ or hand $(59.4 \%)$ and neck stiffness $(99.4 \%)$. Half of the study population were found to have neurological deficit. $98.2 \%$ of patients had positive radiological evidence for neck pain. Cervical spondylosis $(85.9 \%)$ was the most commonly observed cause for neck pain. All patients received pharmacotherapy with NSAIDS and muscle relaxants. Diclofenac was the most commonly prescribed NSAID. $45 \%$ of the patients received alternative and complementary treatments for neck pain. Conclusions: NSAIDs and central skeletal muscle relaxants are the commonly prescribed medications and alternative treatments like spinal manipulation and physiotherapy appears to be beneficial in patients with neck pain.
\end{abstract}

Keywords: Cervical spondylosis, Neckpain, NSAIDs, Skeletal muscle relaxants

\section{INTRODUCTION}

Neck pain is one of the major causes of disability and its prevalence rate is more than $30 \%$ per year. Majority of acute attacks of neck pain will subside with or without medications but half of the patients will have persistent symptoms or they will get frequent occurrences. In most studies conducted so far it is observed that neck pain is not a self-limited problem, and that many patients will have long-term symptoms which may be moderately disabling. Hence it should be diagnosed and treated properly. ${ }^{1}$ Risk factors for neck pain included genetics, poor psychological health, mentally and physically stressful jobs and exposure to tobacco. Important information regarding pain, whether it is neuropathic or mechanical, can be revealed by detailed history taking and physical examination. Based on aetiology neck pain can be classified as specific or non-specific neck pain.
Specific neck pain results from an identifiable pain generating mechanism such as the intervertebral disc, cervical facet joints, and nerve root dura. Non-specific neck pain has no identifiable aetiology although it should be aggravated by neck movements. Imaging studies will help to identify the underlying pathology and magnetic resonance imaging is usually considered for patients with focal neurological deficits, pain not responding to conventional treatment and when an interventional treatment is indicated. ${ }^{2-4}$

Only few clinical studies have evaluated different treatment modalities for neck pain. Skeletal muscle relaxants along with analgesics are found to be beneficial in neck pain, presenting with or without radicular symptoms. There is some evidence to support exercise and heat or cold compresses. This study was done to 
evaluate the socio demographic profile, diagnostic approaches and treatment options for neck pain.

\section{METHODS}

This was a cross sectional study conducted in the outpatient Department of Physical Medicine and Rehabilitation, in a tertiary care hospital during the period of October 2010 to March 2011. A total of 170 patients, satisfying the inclusion criteria were included in the study. Inclusion criteria consisted of patients complaining of pain anytime within the last 7 days and age between 18-65 years. Pregnant and lactating women, those with history of epilepsy, and those with cognitive deficit were excluded from the study. Structured performa validated by the statistician was used for data collection.

Research committee and Ethics committee approval were obtained. Patients satisfying the inclusion criteria were enrolled in the study. A written informed consent was obtained from the patient. Study comprehended single patient visit and information regarding patient demographics, past history, concomitant diseases and medications he/she were on, was obtained from the patient / care giver. All the information collected from each patient was recorded in the pre-prepared proforma. Data regarding the symptoms of the disease and clinical diagnosis were also recorded. Drugs prescribed to each patient included in the study were also noted. Clinician's opinion about patient's X-ray of cervical spine and the data regarding baseline investigations like routine blood examination and fasting blood sugar were also recorded in the proforma. Data analysis was done with the help of excel 2007 and SPSS 16 statistical software.

\section{RESULTS}

170 patients with neck pain registered in the PMR outpatient Clinic at Government Medical College Hospital between October 2010 to March 2011, were selected for the study. The data related to each drug is evaluated and statistical analysis was done. The age range of patients included in the study was between 18 and 65 with a mean age of $47.41 \pm 9.76$ years and the median age was 48 (Table 1). Majority of patients $(74.1 \%)$ included in the study were females and $61.8 \%$ of the patients were manual labourers (Figure 1).

Table 1: Age wise distribution of patients.

\begin{tabular}{|lll|}
\hline Age interval(years) & Number & $\%$ \\
\hline $20-29$ & 6 & 3.5 \\
\hline $30-39$ & 28 & 16.5 \\
\hline $40-49$ & 66 & 38.8 \\
\hline $50-59$ & 50 & 29.4 \\
\hline$>60$ & 20 & 11.8 \\
\hline
\end{tabular}

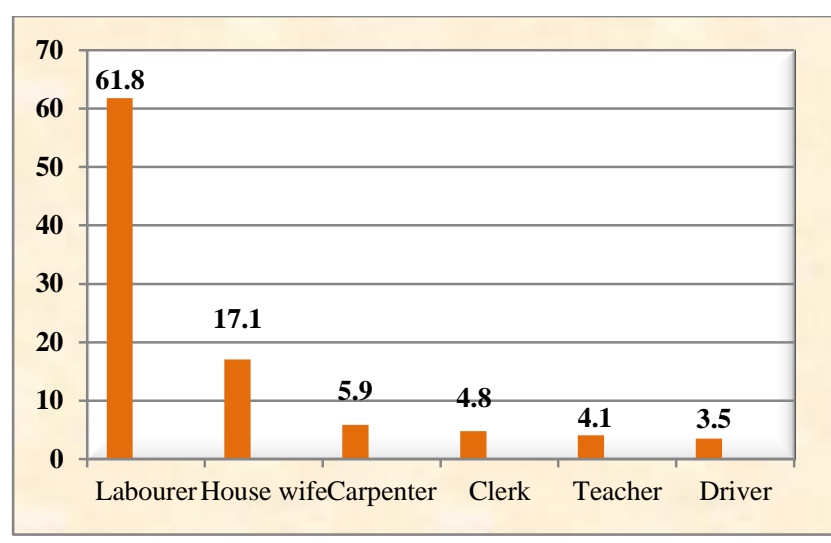

Figure 1: Occupational status of patients.

$14.1 \%$ of patients had sustained neck injury in the past and the remaining population did not give any history of neck injury.98.8\% of patients experienced radiation of neck pain to one or both arms. Patients also gave history of numbness in arm, forearm or hand (Figure 2). 99.4\% patients complained about associated stiffness of neck and $87.1 \%$ of patients had shoulder stiffness.

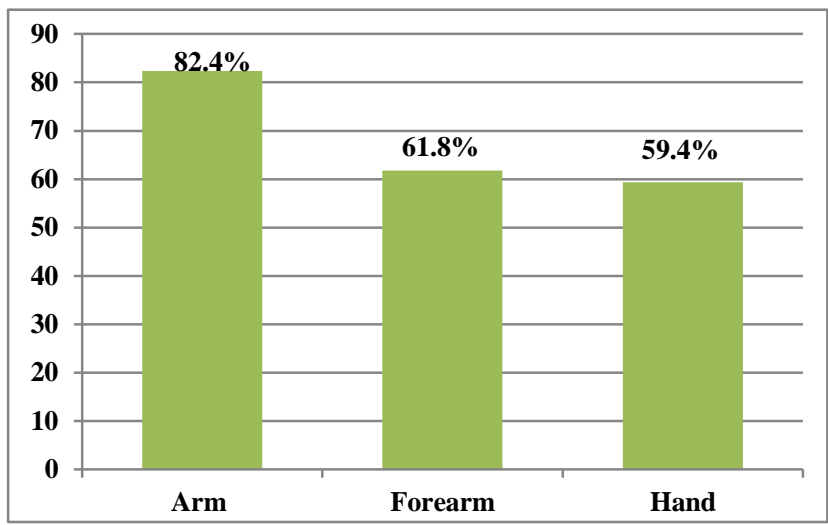

Figure 2: Percentage of patients with numbness in arm/ forearm/ hand.

On examination $98.2 \%$ of patients had tenderness in the neck and only $6.5 \%$ of the patients had a spinal deformity. $50 \%$ of the study population were found to have neurological deficit associated with neck pain. 98.2\% of patients had positive radiological evidence for neck pain. Majority of patients $(85.9 \%)$ are diagnosed to have cervical spondylosis (Figure 3 ).

The most common co morbidity associated with neck pain was hypertension $(23.5 \%)$ followed by diabetes mellitus (18.8\%), coronary artery disease (12.9\%), and dyslipidemia $(11.8 \%)$. Osteoarthritis is another co morbidity which occurred in $10.6 \%$ of patients. $8.2 \%$ of patients in the study population were observed to have Thyroid disorders. $4.7 \%$ were found to be asthmatic and $3.5 \%$ of patients are observed to have renal diseases. periarthritis of shoulder was seen in $3.5 \%$ of patients and $2.4 \%$ of patients had migraine as co morbidity. $1.2 \%$ of patients were found to have COPD. 


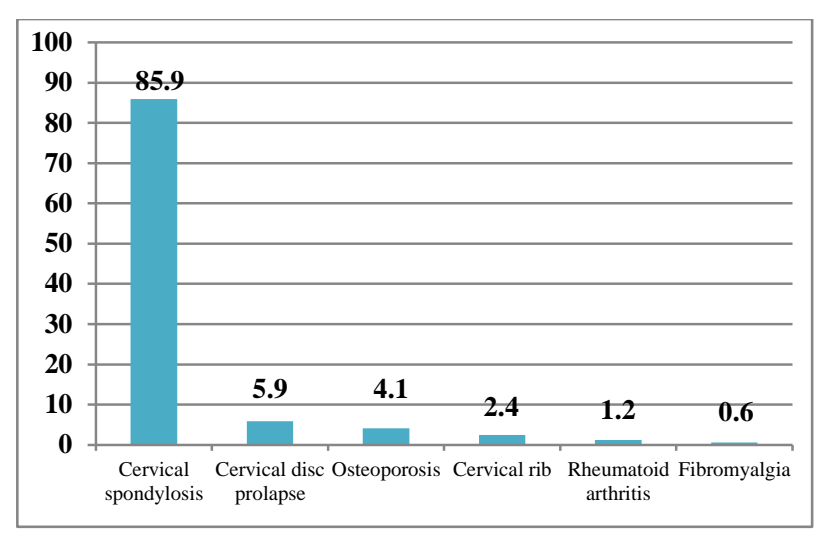

Figure 3: Distribution of diagnosis.

All the patients received NSAIDS and skeletal muscle relaxants. Diclofenac was the most frequently prescribed NSAID (Table 2). Half of patients received centrally acting skeletal muscle relaxant. Thiocolchicoside and rest of the population received Tolperisone to relieve spasticity of neck muscles. Tricyclic antidepressants, Gastroprotective agents (PPI/H2 antagonist), vitamin B12 are the other concomitant medications prescribed to the patients.

Table 2: Use of NSAIDS in patients with neck pain.

\begin{tabular}{|lll|}
\hline NSAID & Patient (n) & Percentage (\%) \\
\hline Diclofenac & 41 & 24 \\
\hline Indomethacin & 10 & 5.8 \\
\hline Aceclofenac & 27 & 15.8 \\
\hline Piroxicam & 15 & 8.8 \\
\hline Ibuprofen & 20 & 11.7 \\
\hline Naproxen & 38 & 22.4 \\
\hline Meloxicam & 4 & 2.3 \\
\hline Coxibs & 5 & 2.9 \\
\hline Paracetamol & 10 & 5.8 \\
\hline
\end{tabular}

$45 \%$ of the patients received alternative and complementary treatments for Neck Pain which included spinal manipulation (2.9\%), traction (12.3\%), physiotherapy $(27.6 \%)$ and electrotherapy (1.8\%).

\section{DISCUSSION}

Neck pain or cervicobrachialgia is a common problem seen in all age group. The physical, psychological, and socioeconomic impact of neck pain is underappreciated. According to the Global Burden of Disease 2010 Study, neck pain is the fourth leading cause of years lost to disability, ranking behind back pain, depression, and arthralgias. ${ }^{5}$ Approximately half of all individuals will experience a clinically important neck pain episode over the course of their lifetime. ${ }^{1}$ There is substantial heterogeneity in the reported prevalence rates of neck pain; however, most epidemiological studies report an annual prevalence ranging between $15 \%$ and $50 \%$,with one systematic review reporting a mean rate of $37.2 \% .^{1,2}$
The prevalence of neck pain is higher in females and peaks in middle age. ${ }^{1,2}$ In the present study also majority of patients belong to the age group of 40-49 years and mean age of patients in this study is 47.41 years and majority of patients in this study were females $(74.1 \%)$. The study by Zhen PC, Zhu LG et al showed female predominance $(69 \%){ }^{6}$ In contrast to that the studies done by Furlan JC, Kalsi-Ryan S and Wang MC, Kreuter W, Wolfla CE, et al more than $50 \%$ of patients were males. ${ }^{7,8}$

Considering the socioeconomic status, in the present study, majority of the patients were manual labourers in both treatment groups $(61.8 \%)$. The results agreed with observations in previous studies which had shown that mentally and physically stressful job is a major risk factor for cervicobracialgia. ${ }^{9}$ Although certain occupations such as office and computer workers, manual labourers, and health care workers, have been found in some studies to have a higher incidence of neck pain, the major workplace factors associated with the condition are low job satisfaction and perceived poor workplace environment. $^{10}$

Unique risk factors for neck pain include trauma (e.g., traumatic brain and whiplash injuries) and certain sports injuries (eg, wrestling, ice hockey, football).In our study $14.1 \%$ of the patients gave a history of neck injury. In a study conducted by, Donald R Murphy et al it is found that individuals who have experienced trauma in the neck are at increased risk of developing neck pain and $20 \%$ of patients in his study had neck injury. ${ }^{11}$

The present study also revealed that $98.8 \%$ of patients experienced radiation of neck pain which is a characteristic feature of cervical radiculopathy caused by compression of the nerve root. ${ }^{6,9}$ This goes hand in hand with the study done by Zhen PC, Zhu LG et al, when also it is observed that majority of conditions causing cervicobrachialgia are associated with radiculopathy. ${ }^{6}$ Numbness and paresthesia are another common features of cervical radiculopathy and in this study most patients had numbness in arm (82.4\%), forearm $(61.8 \%)$ and hand $(59 \%) .^{12}$

Neck pain is associated with several comorbidities including headache, back pain, arthralgias, and depression. Several studies have shown that degenerative changes and disease processes in the cervical spine can lead to reflex spasm of related muscles. ${ }^{9} 99.4 \%$ of patients experienced neck stiffness and $87.1 \%$ patients experienced shoulder stiffness. $98.2 \%$ of the total population experienced tenderness due to spasm of paraspinal muscles.

Spinal deformities like kyphosis, scoliosis and congenital abnormalities of cervical spine can predispose to neurologic injury and chronic neck pain. The study done by Anthony P. Trenga et al showed that $8 \%$ of patients who presented with cervicobrachialgia had spinal 
deformity. ${ }^{13}$ In the present study the incidence of spinal deformity was found to be $6.5 \%$.

Myelopathy is invariably caused by compression of the spinal cord. The spinal cord must be subjected to at least $40 \%$ compression to produce neurological deficits. ${ }^{7,9} 50 \%$ of patients included in the study were found to have neurological deficits on clinical examination. In a previous study done by Okada E, Matsumoto M, et al the incidence of neurological deficit was $42 \%{ }^{14}$

Most of the conditions causing cervicobrachialgia can be diagnosed on the basis of radiological evidence. In a study done by Kieran Michael et al the diagnosis of cervicobrachialgia was supported by radiological evidence in majority of patients in which $85 \%$ of patients had radiological evidence for cervicobrachialgia. ${ }^{9}$ In the present study also $98.2 \%$ of the patients had relevant radiological findings at the time of inclusion in to the study.

In the present study majority of patients $(85.9 \%)$ were diagnosed to have cervical spondylosis. According to many previous studies in this contest, cervical spondylosis is the commonest cause of cervicobrachialgia and age as the major predisposing factor for developing Cervical spondylosis. ${ }^{9,12,14}$ The study done by Okada E, Matsumoto $\mathbf{M}$, et al in Japanese patients showed that majority of patients with cervicobrachialgia had cervical spondylosis. $^{14}$

As per the present study, other major causes of cervicobrachialgia are cervical disc prolapse $(5.9 \%)$, osteoporosis $(4.1 \%)$, cervical rib $(2.4 \%)$, rheumatoid arthritis $(1.2 \%)$ and fibromyalgia $(0.6 \%)$. Most common co morbidity in the current study is hypertension $(23.5 \%)$ followed by diabetes mellitus $(18.8 \%)$, coronary artery disease (12.9), and dyslipidemia (11.8\%). In a study conducted in US, Lad SP, Patil CG et al also showed similar incidence of co morbidities like hypertension $(30 \%)$, diabetes mellitus $(28 \%)$ and other $(37 \%) .{ }^{15}$ But the frequency of co morbidities varies in different populations.

Few high-quality studies have evaluated pharmacotherapy for neck pain. Systemic non-steroidal anti-inflammatory drugs (NSAIDs) have been found to be beneficial for spinal pain in general but have not been formally studied in neck pain. Although NSAIDs are more efficacious than acetaminophen, the American College of Rheumatologists recommends acetaminophen as a first-line treatment, even for arthritis, because of its more favourable adverse effect profile. ${ }^{16}$ In the present study drug therapy for pain relief mainly included NSAIDS, muscle relaxants, tricyclic antidepressants which goes hand in hand with the findings in the previous studies. ${ }^{17-19}$ Previous studies also showed the effectiveness of alternative and complementary treatment in neck pain like spinal manipulation and physiotherapy. ${ }^{19,20}$

\section{CONCLUSION}

Neck pain is one of the leading causes of disability in the world, yet the amount of research devoted to treatment is relatively low in comparison to the other leading causes. For acute neck pain, most cases will resolve spontaneously over a period of weeks to months, but a substantial proportion of individuals will be left with residual or recurrent symptoms. Treatment appears to have little effect on the course of acute neck pain. History and physical examination may provide important clues as to whether the pain is neuropathic or mechanical. NSAIDs and central skeletal muscle relaxants are the commonly prescribed medications and alternative treatments like spinal manipulation and physiotherapy appears to be beneficial in patients with neck pain.

\section{ACKNOWLEDGEMENTS}

I extend my sincere gratitude to the Head of department and other colleagues in the Department of Pharmacology and staff of the Department of Physical medicine and Rehabilitation for their help and valuable suggestions. I am extremely grateful to the patients who agreed to be part of this study, without whose co-operation this study would have been impossible.

Funding: No funding sources

Conflict of interest: None declared

Ethical approval: The study was approved by the Institutional Ethics Committee

\section{REFERENCES}

1. Fejer R, Kyvik KO, Hartvigsen J. The prevalence of neck pain in the world population: a systematic critical review of the literature. Eur Spine J. 2006;15:834-48.

2. Strine TW, Hootman JM. US national prevalence and correlates of low back and neck pain among adults. Arthritis Rheum. 2007;57:656-65.

3. Son KM, Cho NH, Lim SH, Kim HA. Prevalence and risk factor of neck pain in elderly Korean community residents. J Korean Med Sci. 2013;28:680-6.

4. Kääriä S, Laaksonen $\mathrm{M}$, Rahkonen $\mathrm{O}$, Lahelma E, Leino-Arjas P. Risk factors of chronic neck pain: a prospective study among middle-aged employees. Eur J Pain. 2012;16:911-20.

5. US Burden of Disease Collaborators. The state of US health, 1990-2010: burden of diseases, injuries, and risk factors. JAMA. 2013;310:591-608.

6. Zhen PC, Zhu LG, Gao JH, Yu J, Feng MS, Wei X et al. Clinical observation on improvement of motion range of cervical spine of patients with cervical spondylotic radiculopathy treated with rotationtraction manipulation and neck pain particles and cervical neck pain rehabilitation exercises. Zhongguo Gu Shang. 2010;23(10):750-3.

7. Furlan JC, Kalsi-Ryan S, Kailaya-Vasan A, Massicotte EM, Fehlings MG. Functional and clinical 
outcomes following surgical treatment in patients with cervical spondylotic myelopathy: a prospective study of 81 cases. J Neurosurg Spine. 2011;14(3):348-55.

8. Wang MC, Kreuter W, Wolfla CE, Maiman DJ, Deyo RA. Trends and variations in cervical spine surgery in the United States: Medicare beneficiaries, 1992 to 2005. Spine. 2009;34(9):955-61.

9. Hirpara KM, Butler JS, Dolan RT, O'Byrne JM, Poynton AR. Nonoperative Modalities to Treat Symptomatic Cervical Spondylosis. Adv Orthop. 2011;20(11):29-48.

10. May S, Gardiner E, Young S, Klaber-Moffett J. Predictor variables for a positive long-term functional outcome in patients with acute and chronic neck and back pain treated with a McKenzie approach: a secondary analysis. J Man Manip Ther. 2008;16:15560 .

11. Murphy DR, Coulis CM, Gerrard JK. Cervical spondylosis with spinal cord encroachment: should preventive surgery be recommended. Spine J. 2010;10(10):916-7.

12. Lipetz JS, Lipetz DI. Disorders of the cervical spine. In DeLisa, Joel A, Gans, Bruce M editors. Physical Medicine and Rehabilitation: Principles and Practice. 4th Edition, Lippincott Williams and Wilkins. 2005;1(27):610-33.

13. Trenga AP, Singla A, Feger MA, Abel MF. Patterns of congenital bony spinal deformity and associated neural anomalies on X-ray and magnetic resonance imaging. J Child Orthop. 2016 Aug;10(4):343-52.
14. Okada E, Matsumoto M, Fujiwara H, Toyama Y. Disc degeneration of cervical spine on MRI in patients with lumbar disc herniation: comparison study with asymptomatic volunteers. Eur Spine J. 2011 Apr;20(4):585-91.

15. Lad SP, Patil CG, Berta S, Santarelli JG, Ho C, Boakye M. National trends in spinal fusion for cervical spondylotic myelopathy. Surg Neurol. 2009;71(1):66-9

16. Flood J. The role of acetaminophen in the treatment of osteoarthritis.Am J Manag Care. 2010;16:S48-54.

17. Childers MK, Borenstein D, Brown RL, Gershon S, Hale ME, Petri M et al. Low-dose cyclobenzaprine versus combination therapy with ibuprofen for acute neck or back pain with muscle spasm: a randomized trial. Curr Med Res Opin. 2005;21(9):1485-93.

18. Borenstein DG. Chronic neck pain: how to approach treatment. Curr Pain Headache Rep. 2007;11(6):436-9.

19. Cohen SP. Epidemiology, diagnosis, and treatment of neck pain. Mayo Clin Proc. 2015;90(2):284-99.

20. Bronfort G, Evans R, Anderson A, Svendsen KH, Bracha Y, Grimm, RH. Spinal manipulation, medication, or home exercise with advice for acute and subacute neck pain: a randomized trial. Ann Intern Med. 2012;156:1-10.

Cite this article as: Joseph LR. Determinants, characteristics and treatment of neck pain in a Tertiary Care Hospital in Kerala. Int J Basic Clin Pharmacol 2017;6:150-4. 